\title{
Pectin: new science and forthcoming applications of the most valued hydrocolloid
}

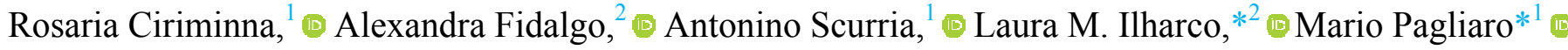 \\ ${ }^{1}$ Istituto per lo Studio dei Materiali Nanostrutturati, CNR, via U. La Malfa 153, 90146 Palermo, Italy \\ ${ }^{2}$ Centro de Química-Física Molecular and IN-Institute of Nanoscience and Nanotechnology, Instituto Superior Técnico, Universidade de Lisboa, Av. Rovisco \\ Pais 1, 1049-001 Lisboa, Portugal
}

\section{ARTICLE INFO}

Keywords:

Pectin

Food hydrocolloid

Green extraction

Heteropolysaccharide

Citrus

Bioeconomy

\section{ABSTRACT}

\section{Introduction}

Abundant in the cell wall of non-graminaceous plants and fruits (more abundant in the pericarp) where it acts as glue facilitating cell adhesion and separation ${ }^{[1]}$ but also modulates cell growth and shape, ${ }^{[2]}$ pectin is nature's structurally most complex polysaccharide. The molecule is a galacturonic acid polymer comprising homogalacturonan (HG), rhamnogalacturonan-I (RGI), rhamnogalacturonan-II (RG-II), arabinogalacturonan (AG), and xylogalacturonan (XGA) regions. Approximately, the polymer consists of repeating units of $(1 \rightarrow 4)-\alpha-D-G a l A$ (galactopyranosyluronic acid) residues, partly methyl-esterified at O-6 position and at lower extent also acetyl-esterified at O-2 or $\mathrm{O}-3$, interrupted by branched regions composed of $(1 \rightarrow 2)-\alpha-\mathrm{L}-$ rhamnose units (RG-I regions) further binding neutral sugars including galactose, arabinose, xylose, and fructose. ${ }^{[3]}$

Commercial production started in the early 1900s. The first plant extracting pectin from citrus fruit peel started in California in $1926,{ }^{[4]}$ and from dried apple pomace in 1934 in Germany. ${ }^{[5]}$ Readily forming a gel in the presence of sugar, pectin was mostly used for the production of jam obtained from fruits poor in pectin such as gooseberries and redcurrants.

Since about a century (the world's first large-scale plant using hydrolysis of protopectin with hot dilute mineral acid started operations in France's Redon in 1941) an highly degraded form of the biopolymer is extracted from citrus peels or apple pomace via prolonged hydrolysis promoted by dilute mineral acid (most often nitric acid) at relatively high temperature $\left(70-80{ }^{\circ} \mathrm{C}\right)$, followed by precipitation with isopropyl alcohol. ${ }^{[6]}$

In general, pectin extracted via the conventional acidextraction process is high methoxyl (HM) pectin, namely pectin with $\mathrm{DE}>50 \%$. Low methoxyl (LM) pectin having with $\mathrm{DE}<$ $50 \%$ (produced by controlled hydrolysis of HM pectin) is more valued than HM pectin because it is able to gel without requiring sugar in a broad $\mathrm{pH}$ range in the presence of small amounts of $\mathrm{Ca}^{2+}$ ions coordinating with free - $\mathrm{COOH}$ groups via the "egg box" cross-linking mechanism. ${ }^{[7]}$

Gelling of HM pectins, on the other hand, requires both high concentration of sugar (usually $>55 \%$ ) and acidic conditions ( $\mathrm{pH}$
$<3.5$ ), which enhanced the demand of LM-pectins as low-calorie thickener and stabilizer in products such as dessert fillings, fruit juices, ice creams, drinking yogurt and dairy drinks. In lowcalorie beverages, for example, LMP is successfully used to impart mouthfeel to the sugar-deprived beverage, being able to "build back body" in acidic beverages. ${ }^{[8]}$

Besides safety and environmental issues related to the use of highly flammable alcohol and vacuum installations posing explosion risks due to explosive alcohol vapor, significant degradation of the original molecular structure of the pectic polysaccharide takes place during the acidic hydrolysis. A significant portion of the "hairy" RG regions of the polymer is lost during the extraction leaving most of the "smooth" $\mathrm{HG}$ regions with a few neutral sugar units bound to the main galacturonic acid chain. ${ }^{[9]}$

Though degraded, commercial pectin is a versatile and safe hydrocolloid widely used by the food and beverage industries as texturizer and gelling agent. ${ }^{[10]}$ Due to its unique physiological activity and exceptional versatility, however, its use is rapidly growing also in many other sectors, including the nutraceutical industry. ${ }^{[1]}$

Driven by the expanding consumer demand for low-calorie and safe food products of good palatability preferably of vegetable origin, in the last decade (2010-2019) the pectin demand has been growing at fast pace. "Despite increases in the raw material prices and shortages of raw material supply" we wrote in 2016 "pectin will replace a number of hydrocolloids that have been used on large scale due to their much lower cost". ${ }^{[6]}$ Five years later, reputed hydrocolloid market analysts reported that pectin had become the third food hydrocolloid in terms of revenues (after gelatin and starches), with sales in 2020 exceeding $\$ 1.25$ billions, and a global output of 70,000 tonnes, having become by far the most valued natural hydrocolloid. ${ }^{[12]}$

Attracting significant interest, ${ }^{[13]}$ the pectin market study published in 2016 offered an insight into a poorly known market amid contradictory information. As mentioned above, in the subsequent five years the global production of pectin has substantially expanded. New pectin plants started operations, 
while incumbent companies expanded the capacity of their plants.

Since more than a decade research on pectin is flourishing at unprecedented levels. Recently named "a universal medicine" in light of its broad physiological activity, ${ }^{[14]}$ pectin also exerts antibacterial activity, a most important property which has been literally rediscovered. ${ }^{[15]}$ Recently, for example the broad-scope antibacterial activity of a new citrus pectin ("IntegroPectin") obtained from lemon and grapefruit processing waste via hydrodynamic cavitation has been demonstrated in vitro, suggesting the origins of said enhanced antimicrobial activity. ${ }^{[16]}$

"Tremendous progress in our understanding of the very complex fine structure of pectic polymers" wrote in 2006 researchers at a large pectin manufacturer, allow producers "to develop a new generation of sophisticated designer pectins with specific functionalities". ${ }^{17]}$

In this study, we offer a unified perspective on the new science and technology of pectin. Accordingly, we offer an insight into forthcoming pectin uses from an expanded perspective taking into account selected technology and economic factors that, we argue in this study, will shortly impact the pectin production and uptake in many countries. Furthermore, we offer an insight into forthcoming pectin uses from an expanded perspective taking into account selected technology and economic factors that, we argue in this study, will shortly impact the pectin production and uptake in many countries.

\section{New insight on structure and physiological role}

Following the determination of the primary structure and early X-ray diffraction studies in the $1940 \mathrm{~s},{ }^{[18]}$ research on the structure of pectin, especially related to conformation, re-started in the 1990s, using new diffraction and microscopy techniques. For instance, using small-angle neutron scattering Perez and coworkers in 1996 showed the main difference between the two main commercial pectins. ${ }^{[19]}$ Having a significantly higher degree of branching imparted by neutral sugars on more numerous RG-I chains, apple pectin in solution is more flexible than citrus pectin of similar degree of methylation, forming more viscous hydrogels.

Almost concomitantly, in a series of studies started in the mid 1990s shortly after the introduction of single molecule atomic force microscopy (AFM) imaging able to produce subnanometre scale images of a biopolymer, Morris and co-workers revealed the morphologies of individual polymers within pectin samples. In general, as put it by Zdunek, whose team in Poland has made substantial contrbutions to the study of the structure of pectins using the same technique, AFM unveils pectin conformation since it allows to measure the force-extension curve of the pectin molecules deposited on mica, which is directly related to its stiffness or flexibility. ${ }^{[20]}$

For example, AFM imaging of pectin extracts from mature green tomatoes subjected to acid hydrolysis in $0.1 \mathrm{M} \mathrm{HCl}$ at 80 ${ }^{\circ} \mathrm{C}$ for $1,8,24$ and $72 \mathrm{~h}$ unveils the structure of pectin in solution (Figure 1). ${ }^{[21]}$ The polymer structures observed show individual strands of lengths lengths ranging from 20 to $400 \mathrm{~nm}$ with diameters in the range $0.5-0.8 \mathrm{~nm}$, commensurate with the expected diameters of single polysaccharide strands adopting a helical conformation when imaged by AFM, and complexes with widths or heights greater than those measured for single strands. The complexes range in size in all three dimensions from one to tens or even hundreds of $\mathrm{nm}$.
Figures 1e, 1f and $1 \mathrm{~g}$ show these complexes sharing two common features: the presence of a backbone structure in the aggregate and the emergence of one or more polymer strands resembling the individual polymer strands. In brief, progressively smaller complexes are observed as the hydrolysis proceeds, suggesting that hydrolysis initially disrupts the associations that give rise to the complexes. Finally, the images of the polymers after $72 \mathrm{~h}$ hydrolysis show a clear reduction in average polymer length with only a few small complexes present in the samples.

In brief, the AFM imaging analysis confirms that acid hydrolysis degrades the RG-I polymer chains with the complexes being degraded into their constituent parts, whereas the individual $\mathrm{HG}$ chains retain molecular weights similar to their initial values. After $72 \mathrm{~h}$ of hydrolysis only trace amounts of arabinose, galactose and rhamnose remain and the observable pectin structures consist of individual HG polysaccharides and HG aggregates.
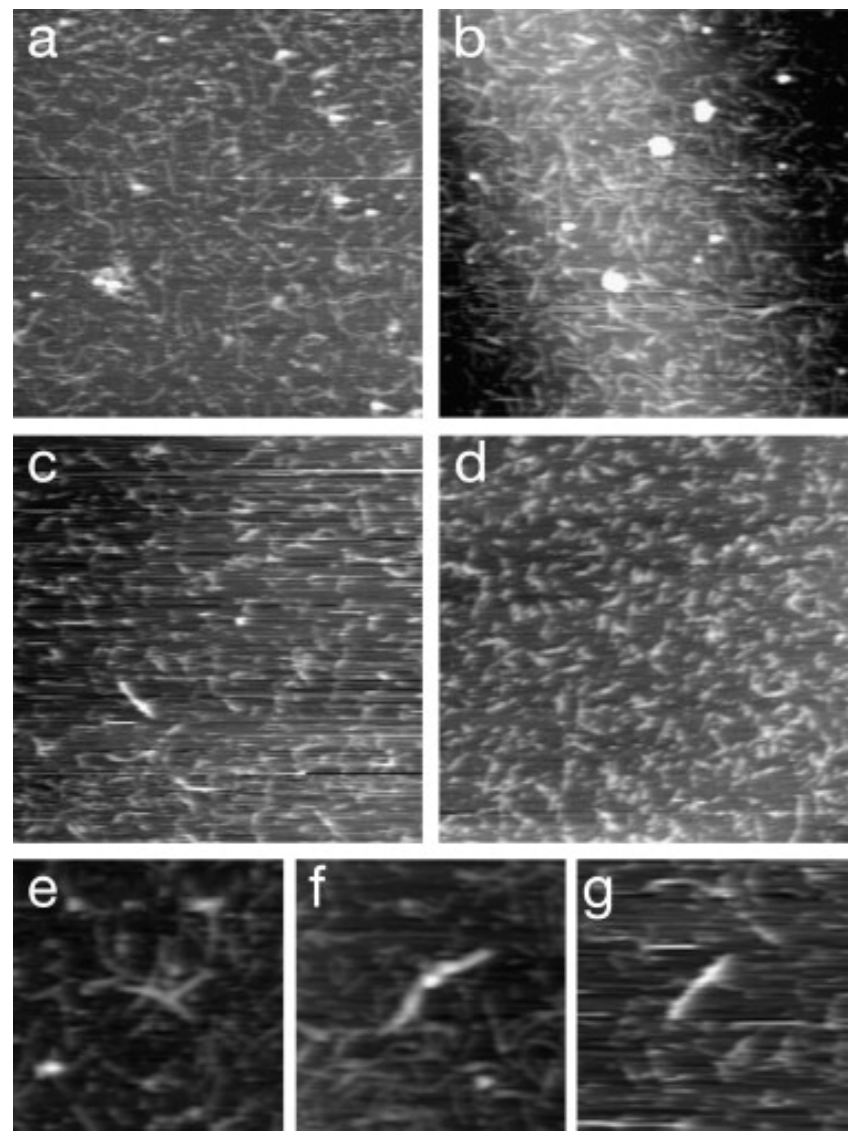

Figure 1. AFM images of pectin during acid hydrolysis. (a) $1 \mathrm{~h}$, (b) $8 \mathrm{~h}$, (c) $24 \mathrm{~h}$, (d) $72 \mathrm{~h}$ of hydrolysis, all images $1 \mu \mathrm{m} \times 1 \mu \mathrm{m}$, height 3 $\mathrm{nm}$. (e-g) High resolution images of examples of complexes, all images $200 \mathrm{~nm} \times 200 \mathrm{~nm}$, height $3 \mathrm{~nm}$. [Reproduced from Ref.22, with kind permission].

Ten years later, Zdunek and co-workers reported that apple pectin instead is chiefly composed of long linear chains of homogalacturonan with bend points with arabinan-rich structures amorphously aggregated around the linear HG chains clearly visible on AFM images (Figure 2). ${ }^{[22]}$ Arabinan was found to be the second most abundant polysaccharide in apple pectin.

The structural characterization of bend points showed that linear molecules are formed by two sections of homogalacturonan separated by a single rhamnose unit, that AFM imaging shows to be a common feature of the molecular 
structure of apple pectin, suggesting a possible role in the networking of pectic polysaccharides.

In agreement with simulations suggesting that arabinan exhibits a very high degree of flexibility, the team proposed that branch and bend points having similar values of experimental (bend and branch) angles and similar lengths (of bend and branch sections) are formed by single interspersions of rhamnose connecting three homogalacturonan chains of rhamnogalacturonan-I with the homogalacturonan side branch (Figure 3).
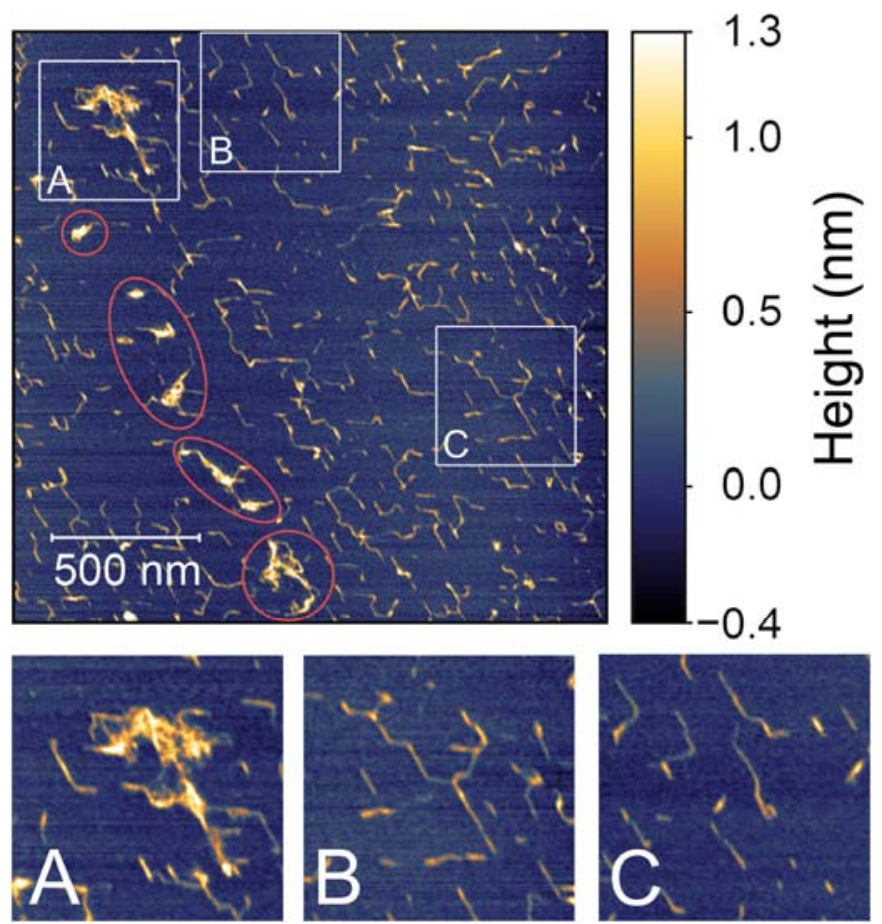

Figure 2. Alkaline-extracted apple pectin deposited on mica, with magnified characteristic structures in AFM imaging: A) amorphous aggregates around linear molecules, B) branched rod-like molecules, C) linear unbranched molecules with bend points. [Reproduced from Ref.23, with kind permission].

Rhamnose interspersions within the HG chains lead to kinked rods with higher degree of mobility as well as the greater number of segments increasing the number of possible interactions with surrounding molecules and thus increase the tendency of gel formation.

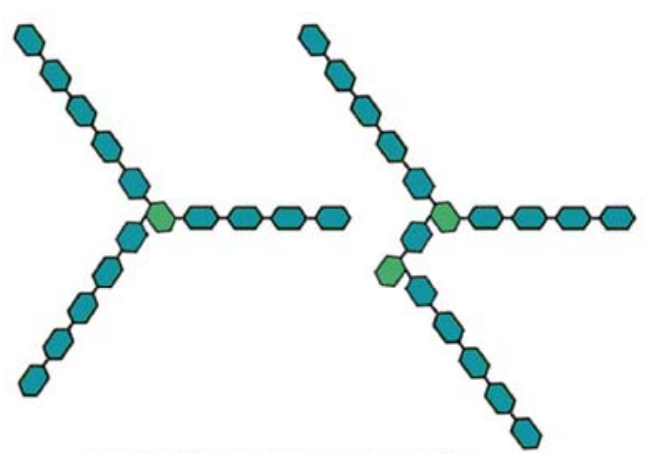

D-Galacturonic acid

L-Rhamnose

Figure 3. Hypothetical pectic structures responsible for the occurrence of branch points in alkaline-extracted apple pectin. [Reproduced from Ref.23, with kind permission].
This model would also explain the key role of rhamnose in apple pectin regardless of its low abundance.

New research on the primary and secondary structure of pectins is driven by the now well established finding that the structure of pectin is eminently affected both by the fruit/plant and by the extraction procedure, which in its turn alters both the rheological properties of the hydrogels (so far the main commercial applications) and the bioactivity of the extracted pectin.

Recently for instance schoolars in India used molecular docking investigation to mulberry pectin extracted from two fruit varieties (BR-2 and S-13) against six bacterial strains and two human cancer cell lines (HT-29 and Hep G-2). ${ }^{[23]}$ The BR-2 mulberry fruit had both the highest antibacterial and cytotoxic activity (against the Hep G-2 cell line, both tested pectins had no cytotoxicity on colon cancer cell line HT-29). Based on molecular interaction through docking, pectin binds effectively with the 1e3g, 3t0c, 5czz, 6j71, 6v40, 5ibs, 5zsy, and 6ggb receptors involved in bacterial infections and carcinogenesis.

On the other hand, it is now clear that simplistic representations of pectin as a GalA tetramer of units (the model used in the aforementioned molecular docking simulation), or as a linear chain of GalA units such as that often portrayed by chemistry and food chemistry magazines ${ }^{[24]}$ are inadequate to represent the structure and the broad biological and rheological properties of pectins. For instance, in plant growth the RG-I and RG-II chains play a crucial role, suggesting "specificities in pectin-mediated cell adhesion that extend beyond a simple story where pectin-equals-glue". ${ }^{[1]}$

\section{New advanced biomaterials}

From pectin-based aerogels to pectin-based implants, a number of different pectin-based advanced materials have been developed in the last decade. Two examples, namely aerogels and implantable and prosthetic devices based on pectin, suffice to render the scope and the potential of this exceptional biomaterial in materials science and technology. Biobased pectin aerogels, for instance, have thermal conductivity values similar to those of silica aerogels, but they do not break under compression, suggesting their use for thermal insulation applications. ${ }^{[25]}$
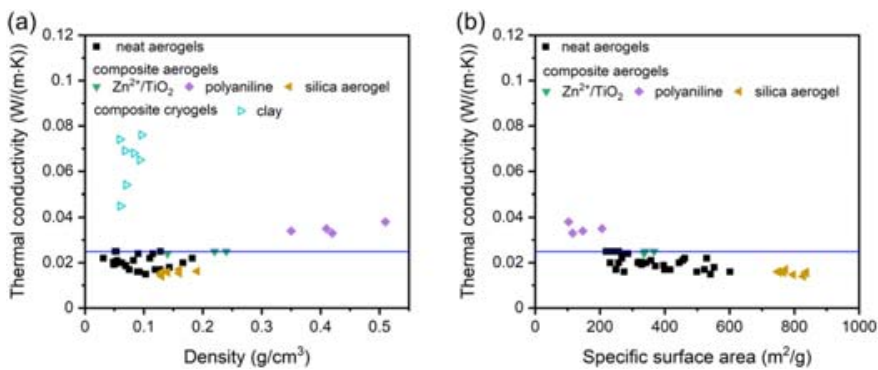

Figure 4. Thermal conductivity of neat and composite pectin aerogels (filled points) and cryogels (open points) as a function of density (a) and specific surface area (b). Blue solid line corresponds to the thermal conductivity of air. [Reproduced from Ref.26, with kind permission].

The lowest value of conductivity, around $0.015 \mathrm{~W} / \mathrm{m} \mathrm{K}$, thermal superinsulating materials (Figure 4) was obtained for aerogels made from non-gelled pectin solutions, at $\mathrm{pH} 2$ and pectin concentration of $2 \mathrm{wt} \%$. Contrary to brittle silica aerogels requiring reinforcement strategies such as addition of glass or 
cellulose fibers or cross-linking, such modifications would not be required for pectin aerogels.

Budtova's team has made substantial contributions to advance the science of pectin-based aerogels. Asked to comment whether pectin could be suitable for the commercial production of biobased aerogels for thermal insulation, Budtova noted how: "additional work is needed to replace drying with supercritical $\mathrm{CO}_{2}$ with a less costly drying process as well as to avoid rapid aging of the pectin aerogel". ${ }^{[26]}$

Silica-based aerogels prepared at low cost via ambient pressure drying from sodium silicate rather than from expensive organosilane precursors have been lately commercialized. ${ }^{[27]}$ The ambient pressure drying process could therefore be easily extended to dry biobased aerogels.

The real problem to be faced for these polysaccharide aerogels is to stabilize them against bacterial degradation. Pectin-based implantable and prosthetic devices seeking practical application, in their turn, only require enhancement of the mechanical properties of scaffold materials made of pectin only. As lately suggested by Indian scholars, beyond biocompatibility and porosity, successful application of biobased scaffolds in regenerative medicine depends on mechanical strength. ${ }^{[28]}$ Readily cross-linked with $\mathrm{Ca}^{2+}$ to form stable (insoluble) films and microparticles, cross-linked pectin is ideally suited to promote osteogenic activity. This was first shown by Wang and co-workers in 2016, using a calcium phosphate/pectin cement (CPCP) scaffold to promote bone tissue growth repair bone defects. ${ }^{[29]}$ We briefly remind that self-setting calcium phosphate cement (CPC) is a bone substitute commonly in bone surgery to enhance the bone healing process. Its main component is $\alpha-$ tricalcium phosphate.
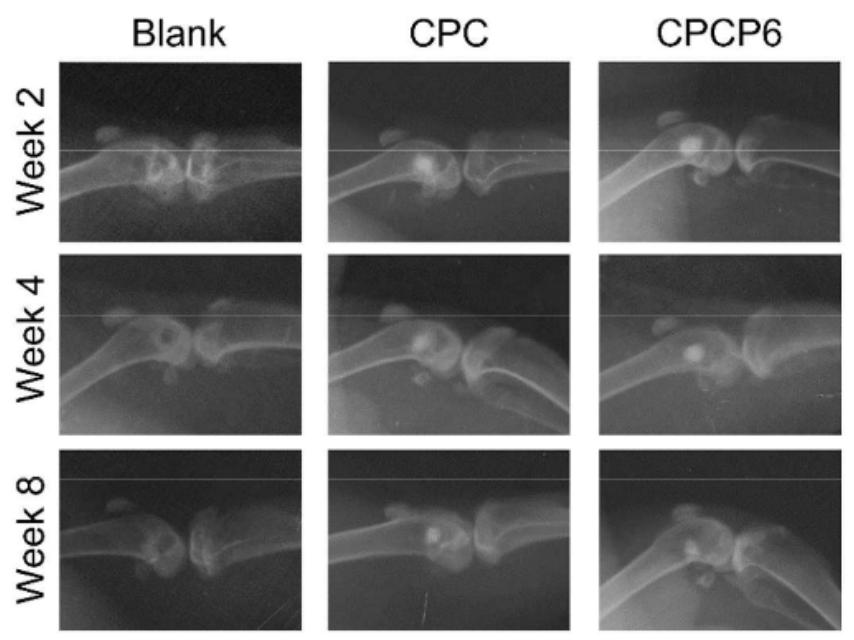

Figure 5. 10 X-rays images of rabbit femur condyle cavity after implanted CPCP scaffolds at different time. [Reproduced from Ref.30, with kind permission].

Adding 6\% pectin to CPC dramatically improved its poor compressive strength, with the compressive strength of the CPCP now approaching $29 \mathrm{Mpa}$, similar to the mechanical strength of cancellous bone. As expected, the introduction of pectin promoted the attachment and proliferation of human adiposederived stem cells (hADSCs) in vitro (Figure 5). In addition, hADSCs seeded onto the CPCP scaffold showed higher osteogenetic efficacy than those seeded onto the CPC scaffold resulting in dramatically higher expression of osteogenic genes when compared to scaffolds formed with calcium phosphate alone (the ALP expression level in the hADSCs from the CPCP6 group was 14-fold higher after 14 days of culture than that at 7 days, whereas the levels in the CPC group only increased approximately 1.5 -fold).

A pre-clinical study on white rabbits using the cavity defect model clearly showed formation of new bone around the CPCP scaffold within 8 weeks. The micro CT image (Figure 5) shows Two weeks after the operation, CPCP6 maintained its form in the cavity, whereas CPC was deformed. Little bone formation was observed 2 weeks after operation. At 4 weeks, the scaffolds still had smooth edges, although some low density material was observed around CPCP6. At 8 weeks, the CPC showed a high density in the cavity, indicating that the scaffold still retained most of the $\mathrm{CPC}$, and only a bone, the newly formed bone was unmature and incoherent. Most important of all, the quantity and quality of the new bone in CPCP group was better than CPC group, indicating that the CPCP scaffold had a better capability of bone regeneration.
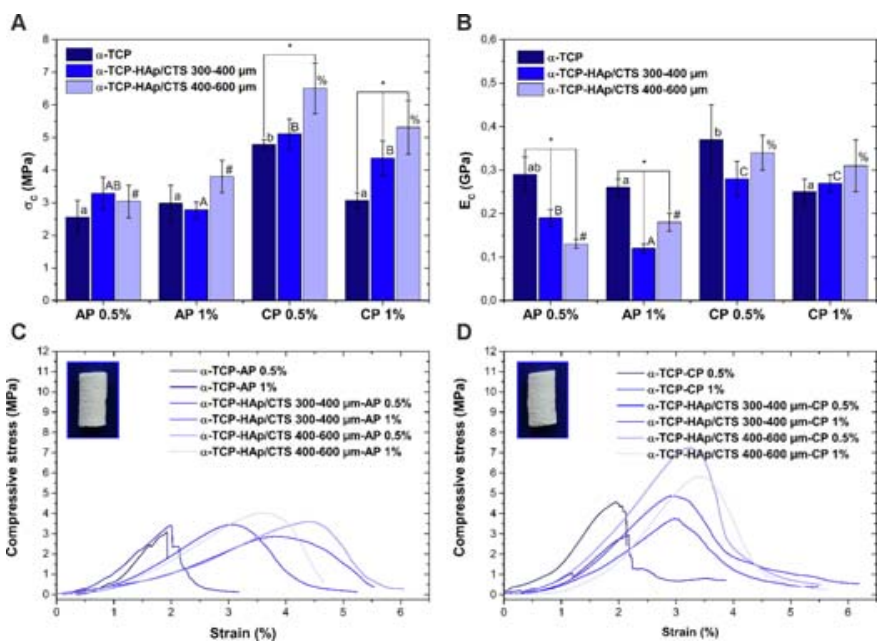

Figure 6. Compressive strength $\sigma_{\mathrm{C}}(\mathrm{A})$ and Young modulus EC (B) of the biomicroconcretes. Statistically significant differences $(p<$ 0.05 ) relative to the control $\alpha$-TCP-based materials are indicated by *. Statistically significant differences $(p<0.05)$ between $\alpha$-TCPbased, $\alpha$-TCP-HAp/CTS300-400 $\mu \mathrm{m}$-based, and $\alpha$-TCPHAp/CTS400-600 $\mu \mathrm{m}$-based materials prepared with the use of various types (AP, $\mathrm{CP}$ ) and concentrations $(0.5 \%, 1 \%)$ of pectins are indicated by $a-b, A-C, \#-\%$, respectively. Compressive stress-strain curves of the biomicroconcretes prepared with the use of AP (C) and CP (D) pectins. Photograph of the $\alpha$-TCP-HAp/CTS300-400 $\mu \mathrm{m}-$ AP0.5\% (C - inset) and $\alpha$-TCP-HAp/CTS300-400 $\mu \mathrm{m}-\mathrm{CP} 0.5 \%$ (D inset) immediately after the compression test. [Reproduced from Ref.31, with kind permission].

This seminal work established the foundation of a new generation of technically and economically viable bone repair healing agents using pectin as key functional agent promoting better and faster bone repair.

Supporting this viewpoint, four years later scholars in Poland used the same approach to enhance the injectability and leaching resistance of CPCP-based biomicroconcretes using apple and citrus LM pectins. ${ }^{[30]}$ Again, the $\alpha$-TCP-based materials showed brittle behaviour, while the presence of apple and citrus LM pectin granules led to ductile characteristics. The biomicroconcretes did not loss their integrity after compression test (Figures 6C,6D - insets) when compared to $\alpha$-TCP-based materials due to above-mentioned interactions between HAp/CTS granules and CPCP scaffolds. Citrus pectin was more effective in improving the compressive strength. 


\section{Economic and industrial aspects}

In the early years after its commercialization, pectin extracted from dried apple pomace was sold as a "jellying solution" in liquid form. Today, it is sold to customers in powder form, most often in "standardized" form adding sugar as functional additive.

As mentioned above, demand is rising at fast pace since more than a decade. For instance, between 2013 and 2018 close to 500 new food products launched had pectin as stabilizing ingredient. $^{[31]}$ The second hydrocolloid used for said new products was carboxymethylcellulose, with slightly more than 100 new products, followed by agar, modified starch, guar, gellan, xanthan, alginate, and carrageenan as preferred stabilizer.

Highly pure pectin is also sold to biomedical and pharmaceutical companies producing medical products (wound dressings and ostomy care products), as well as an excipient or carrier for oral drug delivery systems. ${ }^{[32]}$ Such "pharmaceutical grade" pectin meeting demanding standards for microbiological and chemical purity is sold at prices exceeding $\$ 1,000 / \mathrm{kg}$ for applications such as ostomy formulations improving pouch adhesion and to prevent adhesions after surgical interventions.

In 2002, the global annual pectin consumption was 45,000 tonnes with revenues exceeding $\$ 400$ million. ${ }^{[33]}$ By 2015 , driven by product shortage due to rapid rise in demand, the price of both pectins had crossed the $\$ 15.00 / \mathrm{kg}$ threshold. ${ }^{[6]}$ Another five years and the average price of pectin averaged $\$ 18 / \mathrm{kg}$, with revenues exceeding $\$ 1.25$ billions. $^{[13]}$ In brief, in less than 20 years the market value of pectin has more than tripled.

Table 1. The five pectin largest manufacturers in 2009 (Reproduced from Ref.6, with kind permission)

\begin{tabular}{|l|l|}
\hline Rank & Company \\
\hline 1 & CP Kelco \\
\hline 2 & Danisco \\
\hline 3 & Cargill \\
\hline 4 & Herbstreith \& Fox \\
\hline 5 & Andre Pectin \\
\hline
\end{tabular}

This led to significant changes in the structure of the pectin industry (Table 1). By 2009, there were a few large-scale pectin production plants, nearly all of them in Europe, with one in Mexico, one in Brazil and one in China. ${ }^{[34]}$ Citrus peel (lemon, lime, orange) was the main $(85.5 \%)$ raw material used, followed by apple pomace $(14 \%)$. A minor fraction $(0.5 \%)$ for specific applications was obtained from sugar beet. The fifth largest manufacturer included Yantai Andre Pectin, a joint venture between DSM, a Dutch chemical company, and Shandong Andre Group, a China-based company supplying the raw materials and utilities. Nearly all plants were (and are) highly profitable. For example, the latter China-based company in 2018 recorded sales of about $€ 65$ million with earnings before interest, taxes, depreciation, and amortization (EBIDTA) margin above $25 \%$. ${ }^{[3]}$ A few months later, in early 2019 , DSM acquired majority stake in Andre Pectin for $€ 150$ million. $^{[36]}$

Attracted by similar protability levels, in the subsequent decade a number of new companies started to produce pectin at several new plants located in many countries including Italy and Ukraine.
The top producers, in their turn, further consolidated their activities or sold their plants in a booming market. For example, DuPont in 2011 acquired Danisco (a large enzyme manufacturer producing also pectin). In the same year, Naturex bought Pektowin, a Polish company with a plant producing apple and citrus pectins since 1963. In 2020, Herbstreith \& Fox purchased all Naturex pectin plants from Givaudan (owner of Naturex). One year later, Cargill opened in Brazil its fourth and largest pectin production plant. Thanks to the $\$ 100$ million investment, the company added 6,000 t/a to its production capacity. ${ }^{[37]}$

Other companies such as CP Kelco in Denmark and Ceamsa in Spain expanded their production capacity. The latter, for instance, brought to $1380 \mathrm{t} / \mathrm{a}$ thanks to a new evaporator and a new dryer to separate the alcohol from the precipitated pectin. $^{[38]}$

In general, pectin is costly but it is effective as hydrocolloid at low concentrations. Typical use levels vary between 0.1 and 0.6 per cent in weight, depending on the application. ${ }^{[32]}$ In 2004, the main customers of the pectin industry were the food and beverage companies (Table 2).

Table 2. Main pectin applications in 2004 (Reproduced from Ref.35, with kind permission)

\begin{tabular}{|l|l|}
\hline Application & Market share (\%) \\
\hline High sugar jams & 30 \\
\hline Acidified milk drinks & 15 \\
\hline Low sugar jams & 13 \\
\hline Bakery jams & 9 \\
\hline Yoghurt fruit preparations & 8 \\
\hline Fruit beverages & 8 \\
\hline Confectionery & 8 \\
\hline Pharma/Tobacco & 5 \\
\hline Dairy & 2 \\
\hline Other & 1 \\
\hline
\end{tabular}

In 2010 the European Food Safety Authority (EFSA) recognized pectin as a food supplement capable to reduce postprandial glycaemic responses, maintain normal blood cholesterol concentrations, and increase satiety leading to a reduction in energy intake. ${ }^{[39]}$ In agreement with the European regulation on food supplements, nutraceutical companies can therefore add these health claims in the of pectin-based food supplements commercialized in 27 European countries, thereby originating a completely new demand of pectin from the rapidly growing nutraceutical industry.

Growth of the market demand for pectin from pharmaceutical and nutraceutical is far from being over as new health benefits of pectin, including potential for the treatment of allergies, ${ }^{[40]}$ are reported almost on a monthly basis. Pectin is now widely used in to formulate diarrhoea treatment and wound healing treatments as well as by cosmetic companies for its anti-inflammatory effect on skin, water-holding and lift-restructuring properties. ${ }^{[41]}$

In general, the use and role of pectin in the global current trend towards low-glycaemic foods is already significant. ${ }^{[42]}$

Besides arabinan and rhamnogalacturonan chains, the acidbased extraction process causes the loss of valuable phenolic 
compounds. As put it by Muhidinov and co-workers, ${ }^{[43]}$ separating these materials after the vacuum evaporation and alcohol precipitation (VEAP) purification technology adds cost to the overall production process. Furthermore, the standard process involving the VEAP purification technology poses significant safety issues arising from the use of flammable alcohol (to precipitate pectin) generating explosive vapors in the vacuum installation used to recover the alcohol.

Several alternative processes have been developed to extract less degraded pectin via acid-free technologies. Amid them, microwave-assisted hydrodistillation and gravity, ${ }^{[44]}$ enzymatic degradation using pectin methyl esterase directly captured as recyclable biocatalyst from citrus processing waste, ${ }^{[45]}$ and hydrodynamic cavitation. ${ }^{[46]}$

Being reproducible and scalable, these acid-free and "green" extraction processes hold practical (commercial) applicative potential. For instance, extraction based on hydrodynamic cavitation-based directly carried out on a semi-industrial scale ( $>30 \mathrm{~kg}$ citrus biowaste in $120 \mathrm{~L}$ water), affords pectin in solution and micronized cellulose of high value (CytroCell) $)^{[47]}$ as solid residue through an efficient, one-pot process requiring no chemical reactant (acid, alkali or enzyme) to promote the extraction. The safe and robust hydrodynamic cavitation process for the extraction of natural products is easily scaled-up. ${ }^{[4]}$ In this case, water is the only dispersion medium, and electricity is the unique energy form employed to run the process affording plentiful amounts of two biomaterials (pectin and micronized cellulose) with numerous applications that in the case of micronized cellulose have been limited by multi-step production processes applied to lignocellulosic biomass requiring harsh conditions.

Furthermore advances in purification technology already allow to replace conventional vacuum evaporation and alcohol precipitation (VEAP) technology with diaultrafiltration and concentration using a fiber membrane. ${ }^{[49]}$ Comparison of the pectin structures extracted by flash hydrolysis in dilute mineral acid solution and isolated via VEAP and diaultrafiltration directly on pilot-scale shows that the latter purification process affords (in 2 cycles) pectin with decreased polydispersity and increased molar mass, thanks to the separation of pectin polymers with higher molar mass, at a fraction of the energy requirements of the VEAP process. In detail, the amounts of ethanol and power needed for the isolation of pectin when using the VEAP process are, respectively, twice and four times larger than those used for the isolation of pectin by diaultrafiltration.

Regardless of the method used for pectin extraction, the latter isolation process is general and can be applied to any pectic aqueous solution.

\section{Outlook and conclusions}

Pectin, the plant heteropolysaccharide once used as main ingredient of the "jellying solution" to gel jams, actually is a biomolecule of exceptionally broad physiological properties and uniquely complex primary and secondary structures which make it suitable for widely different applications, from advanced biomaterials through new antimicrobials of broad scope.

Likewise to glycerol, and as usual in chemistry research when a substance knows a quick expansion in demand, intense new research carried out in the last decade (2010-2020) has shed new light on its molecular structure and physiological role, up to new production methods and completely new applications such as pectin aerogels for thermal insulation, and calcium phosphate pectin cements for bone repair.
Investigating the market sustainability of pectin productions taking into account selected economic aspects we found analyses dating back to the early 1990 s reporting that oversupply due to increased capacity and lower worldwide demand drove prices downward. $^{[50]}$

Yet, driven first by the unique performance of pectin in stabilizing milk proteins in acidic dairy beverages such as drinking yoghurts, in only ten years the situation turned out to be completely the opposite. The worldwide consumption of pectin quickly went from $18,000-19,000$ tonnes of the early 1990 s to 30,000 tonnes in 2009. ${ }^{[31]}$ Another decade, and in 2020 the oaverall amount of pectin delivered to ever more numerous customers reached 70,000 tonnes. ${ }^{[10]}$

The pectin industry, an oligopoly of less than 10 companies comprising an highly rewarding niche of the chemical market, underwent profound changes with several new entrants operating new extraction plants and market consolidation amid the top producers. New pectin plants consume a fraction of the water of older plants and use far better precipitation units, dryers, and evaporators reducing the overall energy costs. Yet, all existing plants continue to use the acid-assisted extraction with mineral acid followed by precipitation with alcohol first industrialized in 1941 France's Redon (where also LM pectin was first produced and commercialized).

Several alternative processes have been developed to extract less degraded pectin via acid-free technologies. ${ }^{[45,46,47]}$ Whether or not these technologies will be commercialized will not be due to reduced environmental impact or better product quality (lesser degradation and higher purity), but to their higher profitability due to significantly lower capital and production costs.

Pagliaro has argued elsewhere that reduced "capex" and "opex" (capital and operational expenses) due to new green chemistry production (synthetic or extraction) technologies in much smaller production units operated in continuous mode is a common feature of these technologies that will shortly impact many productions of the global chemical industry. ${ }^{[51]}$ Some of the "green extraction of natural products" ${ }^{[52]}$ technologies based on green chemistry and green engineering share these properties because along with dramatically reduced energy, water and solvent consumption, they have lately become scalable at low capital cost. Indeed, selected chemical engineering firms now commercialize the first pectin extractors based, for example, on acoustic cavitation. Remarkably, one reads on the website of a company commercializing a family of new "small footprint" extractors is already available "for producing large volumes of pectin" via "inline processing" which is "highly efficient, rapid and requires significantly less labour". ${ }^{[3]}$

The world's largest countries, Russia, which is also the world's third country in terms of apple production, does not host a single pectin production plant. So does India, which is a huge producer of both citrus and apple fruits. It is likely that new pectin producers in these countries, but also in other huge countries harvesting large amounts of citrus fruits such as Argentina, Brazil, Mexico and South Africa, will start producing pectin using new extraction and purification (i.e., diaultrafiltration and concentration using a fiber membrane $)^{[50]}$ technologies, whereas existing producers will continue to rely on the acid-extraction technology in modern plants.

In general, the pectin industry will progressively start supplying its valued biomaterial no longer chiefly to customers in the food and beverage industries, but also to companies using pectin to produce advanced biobased materials, nutraceutical, medical and pharmaceutical products. The latter, however, will 
not be niche applications of an "hexotic" polysaccharide commonly used to make jams and drinkable yoghurts, but rather, given its impressive physiological ("a universal medicine") ${ }^{[12]}$ and structural properties, large scale uses of a uniquely complex and highly biocompatible macromolecule.

\section{Conflict of interest}

The Authors declare no conflict of interest.

\section{Acknowledgements}

We thank Professors Tatiana Budtova, Mines ParisTech, France, and Professor Zayniddin K. Muhidinov, Tajikistan National Academy of Sciences, for helpful correspondence concerning the topics of this study.

\section{References}

1. F. Bou Daher, A. Braybrook Siobhan, How to let go: pectin and plant cell adhesion, Front. Plant Sci. 2015, 6, 523. https://doi.org/10.3389/fpls.2015.00523

2. Y. Yang, C.T. Anderson, Biosynthesis, localisation, and function of pectins in plants In Pectin: Technological and Physiological Properties, V. Kontogiorgos (Ed.), Springer, Cham (Switzerland): 2020; pp.1-15. https://doi.org/10.1007/978-3-030-53421-9_1

3. D. Ropartz, M.C. Ralet, Pectin structure In Pectin: Technological and Physiological Properties, V. Kontogiorgos (Ed.), Springer, Cham (Switzerland): 2020; pp.17-36. https://doi.org/10.1007/978-3-030-53421-9_2

4. Z. I. Kertesz, The pectic substances, Interscience, New York: 1951

5. Herbstreith\&Fox, The specialists for pectin, Neuenbürg (Germany): 2009. https://silo.tips/download/the-specialists-for-pectin (accessed November 12, 2021)

6. R. Ciriminna, A. Fidalgo, R. Delisi, L.M. Ilharco, M. Pagliaro, Pectin production and global market, Agro Food Ind. Hi-Tech 2016, 27, 17-20. https://bit.ly/2ZQ1KEv

7. W. Han, Y. Meng, C. Hu, G. Dong, Y. Qu, H. Deng, Y. Guo, Mathematical model of $\mathrm{Ca}^{2+}$ concentration, $\mathrm{pH}$, pectin concentration and soluble solids (sucrose) on the gelation of low methoxyl pectin, Food Hydrocoll. 2017, 66, 37-48.

8. J. Gelski, When sugar comes out, hydrocolloids put body and mouthfeel back in, Food Business News, April 4, 2018. https://www.foodbusinessnews.net/articles/11592-when-sugar-comesout-hydrocolloids-put-body-and-mouthfeel-back-in

9. W. Wang, X. Wu, T. Chantapakul, D. Wang, S. Zhang, X. Ma, T. Ding, X. Ye, D. Liu, Acoustic cavitation assisted extraction of pectin from waste grapefruit peels: A green two-stage approach and its general mechanism, Food Res. Int. 2017, 102, 101-110. https://doi.org/10.1016/j.foodres.2017.09.087

10. B. Zeeb, M. Roth, H.-U. Endreß, Commercial pectins In Handbook of Hydrocolloids, $3^{\text {rd }}$ edition, Editor(s): G.O. Phillips, P.A. Williams (Ed.s), Woodhead Publishing, Sawston (Great Britain): 2021; pp.295-315. https://doi.org/10.1016/B978-0-12-820104-6.00019-X

11. R. Ciriminna, N. Chavarría-Hernández, A.I. Rodríguez Hernández, M. Pagliaro, Pectin: A new perspective from the biorefinery standpoint, Biofuels, Bioprod. Biorefin. 2015, 9, 368-377. https://doi.org/10.1002/bbb.1551

12. D. Seisun, N, Zalesny, Strides in food texture and hydrocolloids, Food Hydrocoll. 2021 117

106575 . https://doi.org/10.1016/j.foodhyd.2020.106575

13. By November 12, 2021, only on ResearchGate the study "Pectin Production and Global Market" had been read 17,132 times: https://www.researchgate.net/publication/305687551_Pectin_Production_and Global Market (accessed November 12, 2021).

14. O. Zaitseva, A. Khudyakov, M. Sergushkina, O. Solomina, T. Polezhaeva, Pectins as a universal medicine, Fitoterapia 2020, 146, 104676. https://doi.org/10.1016/j.fitote.2020.104676

15. R. Ciriminna, A. Fidalgo, F. Meneguzzo, A. Presentato, A. Scurria, D. Nuzzo, R. Alduina, L.M. Ilharco, M. Pagliaro, Pectin: A long-neglected broad-spectrum antibacterial, ChemMedChem 2020, 15, 2228-2235. https://doi.org/10.1002/cmdc.202000518

16. A. Presentato, E. Piacenza, A. Scurria, L. Albanese, F. Zabini, F. Meneguzzo, D. Nuzzo, M. Pagliaro, D.F. Chillura Martino, R. Alduina, R. Ciriminna, A new water-soluble bactericidal agent for the treatment of infections caused by Gram-positive and Gram-negative bacterial strains, Antibiotics 2020, 9, 586. https://doi.org/10.3390/antibiotics9090586
17. W.G.T Willats, J.P. Knox, J.D. Mikkelsen, Pectin: new insights into an old polymer are starting to gel, Tr. Food Sci. Technol. 2006, 17, 97-104. doi:10.1016/j.tifs.2005.10.008

18. K. J. Palmer, Merle B. Hartzog, An X-Ray diffraction investigation of sodium pectate, J. Am. Chem. Soc. 1945, 67, 2122-2127. https://doi.org/10.1021/ja01228a022

19. S. Cros, C. Garnier, M.A. Axelos, A. Imberty, S. Pérez, Solution conformations of pectin polysaccharides: determination of chain characteristics by small angle neutron scattering, viscometry, and molecular modeling, $\quad$ Biopolymers $\quad$ 1996, 339-352. https://doi.org/10.1002/(sici)1097-0282(199609)39:3<339::aidbip6>3.0.co;2-p

20. A. Zdunek, P.M. Pieczywek, J. Cybulska, The primary, secondary and structures of higher levels of pectin polysaccharides, Compr Rev Food Sci Food Saf. 2021, 20, 1101-1117. https://doi.org/10.1111/1541-4337.12689

21. A.N. Round, N.M. Rigby, A. J. MacDougall, V.J. Morris, A new view of pectin structure revealed by acid hydrolysis and atomic force microscopy, $\begin{array}{lllll}\text { Carbohydr. } & \text { Res. } & \text { 2010, } & \text { 487-497. }\end{array}$ https://doi.org/10.1016/j.carres.2009.12.019

22. P.M. Pieczywek, A. Kozioł, W. Płaziński, J. Cybulska, A. Zdunek, Resolving the nanostructure of sodium carbonate extracted pectins (DASP) from apple cell walls with atomic force microscopy and molecular dynamics, Food Hydrocoll. $2020,105726$. https://doi.org/10.1016/j.foodhyd.2020.105726

23. R. Venkatesh Kumar, D. Srivastava, V. Singh, U. Kumar, V. Kumar Vishvakarma, P. Singh, D. Kumar, R. Kumar, Characterization, biological evaluation and molecular docking of mulberry fruit pectin, Sci. Rep. 2020, 10, 21789. https://doi.org/10.1038/s41598-020-78086-8

24. See for instance, the structure portrayed at: https://cen.acs.org/articles/91/i29/Pushing-Pectin.html

25. F. Zou, T. Budtova, Polysaccharide-based aerogels for thermal insulation and superinsulation: An overview, Carbohydr. Polym. 2021, 266, 118130. https://doi.org/10.1016/j.carbpol.2021.118130

26. Prof. T. Budtova, personal corrspondence with M.P., November 2021.

27. N. Minju, B.N. Nair, S. Savithri, Sodium silicate-derived aerogels: effect of processing parameters on their applications, RSC Adv. 2021, 11, 15301-15322. https://doi.org/10.1039/D0RA09793D

28. A. Indurkar, A. Pandit, R. Jain, P. Dandekar, Plant-based biomaterials in tissue engineering, Bioprinting 2021, 21, e00127. https://doi.org/10.1016/j.bprint.2020.e00127

29. L. Zhao, J. Li, L. Zhang, Y. Wang, J. Wang, B. Gu, J. Chen, T. Hao, C. Wang, N. Wen, Preparation and characterization of calcium phosphate/pectin scaffolds for bone tissue engineering, RSC Adv. 2016, 6, 62071-62082. https://doi.org/10.1039/c6ra07800a

30. M. Dziadek, A. Zima, E. Cichoń, J. Czechowska, A. Ślósarczyk, Biomicroconcretes based on the hybrid HAp/CTS granules, $\alpha$-TCP and pectins as a novel injectable bone substitutes, Mater. Lett. 2020, 265, 127457. https://doi.org/10.1016/j.matlet.2020.127457

31. J. Møller, Formulating Ambient Drinking Yoghurt with A Range of Textures - Effect of Stabilizers and Processing, $15^{\text {th }}$ African Dairy Conference and Exhibition, Nairobi, 13-16 August 2019.

32. P. Sriamornsak, Application of pectin in oral drug delivery, Expert Opin. Drug Deliv. 2011, 8, 1009-1023. https://doi.org/10.1517/17425247.2011.584867

33. B.J. Savary, A.T. Hotchkiss, M.L. Fishman, R.G. Cameron, R. Shatters, Development of a Valencia orange pectin methyl esterase for generating novel pectin products In Advances in Pectin and Pectinase Research, F. Voragen, H. Schols, R. Visser (Eds.), Kluwer Academic Publishers, Amsterdam: 2003; pp.345-361. http://dx.doi.org/10.1007/978-94-017-0331-4_26

34. J. Staunstrup, Citrus pectin production and world market, The International Citrus \& Beverage Conference, Clearwater, FL, 15-18 September 2009.

35. DSM, DSM announces agreement to increase its shareholding in Andre Pectin from $29 \%$ to $75 \%$, dsm.com, February 4, 2019. https://www.dsm.com/corporate/news/news-archive/2019/03-19-dsmannounces-agreement-to-increase-its-shareholding-in-andre-pectin-from29-to-75-percent.html

36. FoodBev Media, DSM acquires majority stake in Andre Pectin for $150 \mathrm{~m}$ euros, foodbev.com, February 4, 2019. https:/www.foodbev.com/news/dsm-acquires-majority-stake-in-andrepectin-for-150m-euros (accessed November 12, 2021). 
37. A, Mano, Cargill opens new Brazil pectin factory, first outside Europe, Reuters, September 3, 2021. https://www.reuters.com/business/cargill-opens-new-brazil-pectin-

factory-first-outside-europe-2021-09-03/

38. Ceamsa, Ceamsa News, June 2017. https://www.ceamsa.com/wpcontent/uploads/2017/06/CEAMSANEWS_Q2.pdf

39. European Food Safety Authority, Scientific Opinion on the substantiation of health claims related to pectins and reduction of postprandial glycaemic responses (ID 786), maintenance of normal blood cholesterol concentrations (ID 818) and increase in satiety leading to a reduction in energy intake (ID 4692) pursuant to Article 13(1) of Regulation (EC) No 1924/2006, EFSA J. 2010, 8, 1747-1753. https://doi.org/10.2903/j.efsa.2010.1747

40. F. Blanco-Pérez, H. Steigerwald, S. Schülke, S. Vieths, M. Toda, S. Scheurer, The dietary fiber pectin: health benefits and potential for the treatment of allergies by modulation of gut microbiota, Curr. Allergy Asthma Rep. 2021, 21, 43. https://doi.org/10.1007/s11882-021-01020-z

41. O. D. Akin-Ajani, A. Okunlola, Pharmaceutical applications of pectin In Pectins, M.A. Masuelli (Ed.) IntechOpen, Zagreb: 2021. https://doi.org/ 10.5772/intechopen.100152

42. N. Muñoz-Almagro, A. Montilla, M. Villamiel, Role of pectin in the current trends towards low-glycaemic food consumption, Food Res. Int. 2021, 140, 109851. https://doi.org/10.1016/j.foodres.2020.109851

43. Z.K. Muhidinov, I. Khurshed, I. Ikromi, A.S. Jonmurodov, A.S. Nasriddinov, S.R. Usmanova, J.T. Bobokalonov, G.D. Strahan, L.S. Liu, Structural characterization of pectin obtained by different purification methods, Int. J. Biol. Macrom. 2021, 183, 2227-2237. https://doi.org/10.1016/j.ijbiomac.2021.05.094

44. R. Ciriminna, A. Fidalgo, D. Carnaroglio, G. Cravotto, G. Grillo, A. Tamburino, L.M. Ilharco, M. Pagliaro, Eco-friendly extraction of pectin and essential oils from orange and lemon peels, ACS Sustain. Chem. Eng. 2016, 4, 2243-2251. https://doi.org/10.1021/acssuschemeng.5b01716

45. Talekar, S.; Vijayraghavan, R.; Arora, A.; Patti, A. F. Greener production of low methoxyl pectin via recyclable enzymatic de-esterification using pectin methylesterase cross-linked enzyme aggregates captured from citrus peels, Food Hydrocoll. 2020, 108, 105786. https://doi.org/10.1016/j.foodhyd.2020.105786

46. F. Meneguzzo, C. Brunetti, A. Fidalgo, R. Ciriminna, R. Delisi, L. Albanese, F. Zabini, A. Gori, L.B. dos Santos Nascimento, A. De Carlo, F. Ferrini, L.M. Ilharco, M. Pagliaro, Real-scale integral valorization of waste orange peel via hydrodynamic cavitation, Processes 2019, 7, 581. https://doi.org/10.3390/pr7090581

47. A. Scurria, L. Albanese, M. Pagliaro, F. Zabini, F. Giordano, F. Meneguzzo, R. Ciriminna, CytroCell: valued cellulose from citrus processing waste, Molecules 2021, 26, 596. https://doi.org/10.3390/molecules26030596

48. D. Panda, S. Manickam, Cavitation technology - the future of greener extraction method: a review on the extraction of natural products and process intensification mechanism and perspectives, Appl. Sci. 2019, 9, 766. https://doi.org/10.3390/app9040766

49. Z. Muhidinov, K. Teshaev, A. Jonmurodov, D. Khalikov, M. Fishman, Physico-chemical characterization of pectic polysaccharides from various sources obtained by steam assisted flash extraction (SAFE), Macromol. Symp. 2012, 317-318, 142-148. https://doi.org/10.1002/masy.201100108

50. B. Bahner, Pectin oversupply drives prices downward, Chem. Market Rep. 1993, 242, 20-21.

51. M. Pagliaro, An industry in transition: The chemical industry and the megatrends driving its forthcoming transformation, Angew. Chem. Int. Ed. 2019, 58, 11154-11159. https://doi.org/10.1002/anie.201905032

52. F. Chemat, M.A. Vian, G. Cravotto, Green extraction of natural oroducts: concept and principles, Int. J. Mol. Sci. 2012, 13, 8615-8627. https://doi.org/10.3390/ijms13078615

53. Hielscher, Higher pectin yields with ultrasonic extraction, Taltow (Germany), 2021. https://www.hielscher.com/higher-pectin-yields-withultrasonic-extraction.htm (accessed November 12, 2021). 